\title{
Bone Metastases: Experience of Rheumatology Unit of National Hospital University Hubert Koutoukou Maga of Cotonou
}

\author{
Zavier Zomalheto $^{{ }^{*}}$, Olivier Biaou ${ }^{2}$, Patricia Yékpè-Ahouansou2 ${ }^{2}$, \\ Sèdami Narcès Emery Gnankadja ${ }^{1}$, Martin Avimadje ${ }^{1}$ \\ ${ }^{1}$ Rheumatology Department of National Hospital, University Hubert Koutoukou Maga, Cotonou, Benin \\ ${ }^{2}$ Medical Imaging Department of National Hospital, University Hubert Koutoukou Maga, Cotonou, Benin \\ Email: ${ }^{*}$ zozaher@yahoo.fr
}

Received 1 January 2015; accepted 21 January 2015; published 27 January 2015

Copyright (C) 2015 by authors and Scientific Research Publishing Inc.

This work is licensed under the Creative Commons Attribution International License (CC BY).

http://creativecommons.org/licenses/by/4.0/

(c) (i) Open Access

\section{Abstract}

Aim: To determine the epidemiological, diagnosis and treatment of secondary bone cancer at the National Hospital University Hubert Koutoukou Maga of Cotonou. Patients and Method: It was a retrospective descriptive cross-sectional study carried out from January 1999 to December 2013 on the records of patients treated in the rheumatology department. The selected files had radiological images of tumor appearance objectified by two radiologists. The diagnosis of secondary bone cancer was confirmed after a bone biopsy or the discovery of a primitive tumor site. Patients with hematologic malignancy and incomplete or insufficiently explored records were excluded. Results: Among 10,292 patients followed in the service, $51(0.5 \%)$ had documented bone metastasis. The sex ratio was 1.83 . The mean age of patients was $54 \pm 9$ [26 - 85] years, with $53 \%$ of those over 60 years old. Secondary cancers were on the spine $(74.5 \%)$, pelvis $(35.3 \%)$ and the long bones $(39.2 \%)$. The primary cancer most frequently found was that of the prostate and breast (45.1\% and $27.6 \%$, respectively) followed by genital and digestive cancers $(9.8 \%$ and $7.8 \%$, respectively). Treatment was dominated by hormone therapy $(83 \%)$ bisphosphonates $(70.5 \%)$ and chemotherapy (57\%). Conclusion: The profile of bone cancer in Benin hospital is very diverse and dominated by the types and osteolytic ostéocondensant. Primary cancers were dominated by the prostate and breast. Bisphosphonates took an important place in the treatment of the disease.

\section{Keywords}

Metastases, Primary Cancer, Benin

\footnotetext{
${ }^{*}$ Corresponding author.
}

How to cite this paper: Zomalheto, Z., Biaou, O., Yékpè-Ahouansou, P., Gnankadja, S.N.E. and Avimadje, M. (2015) Bone Metastases: Experience of Rheumatology Unit of National Hospital University Hubert Koutoukou Maga of Cotonou. Open Journal of Rheumatology and Autoimmune Diseases, 5, 6-11. http://dx.doi.org/10.4236/ojra.2015.51002 


\section{Introduction}

Bone is the third site of metastasis of cancer after the liver and lungs. This underpins that the bone is a good "soil" for the "seed" tumor. The inaugural metastases are common and represent $22.6 \%$ to $30 \%$ of bone metastases [1]-[3]. The primary focus of these metastases is often the prostate, breast, kidney, lung and thyroid. Cancers of the five foci represent between $80 \%$ and $96 \%$ of cancers responsible bone metastases [2]-[5].

The recognition of a secondary bone tumor based on the comparison of epidemiological, clinical, radiological and pathological. Imaging of bone tumors remains dominated by X-ray.

Their treatment requires a multidisciplinary approach. Radiation therapy is one of the key resources available to treat bone metastases near all medical or surgical arsenals [4]. According to Conroy, the median survival of bone cancer is five months after diagnosis with $5 \%$ at five-year survival and $1 \%$ at ten-year survival [3]. Many African studies have discussed the issue as reflected the recently published [6]-[11]. In Benin, no study has been done on bone metastases. The objective of this study was to clarify the epidemiological, diagnostic and therapeutic aspects of bone metastases in the Rheumatology Department of the National Hospital University Hubert Koutoukou Maga of Cotonou.

\section{Patients and Method}

It was a descriptive and retrospective cross-sectional study, carried out over 15 years from 1999 to December 2013 on the records of patients treated in the rheumatology department. Patients met the following criteria:

- Have consulted or been hospitalized in the rheumatology department during the study period;

- Have presented an inflammatory bone pain or pathological fracture of long or flat bones or bone swelling related to a secondary bone cancer.

The diagnosis of secondary bone cancer was confirmed after a bone biopsy or the discovery of a primitive cancer.

Patients with hematologic malignancy or with incomplete or insufficiently explored records were excluded from the study.

Variables evaluated were: socio-demographic (age, sex), therapeutic itinerary, cliniac features (pain, fever, lameness), radiological, etiological and therapeutic parameters. The statistical analysis of results was performed using Epi info 7.0 software and STATA/IC 11.0.

This investigation was approved by the local Ethics Committee.

\section{Results}

\subsection{Socio-Demographic Data}

Among 10,292 patients seen in the unit of Rheumatology (about 750 patients per year), 51 (0.5\%) had bone metastases. There were 33 men and 18 women (sex ratio $=1.83$ ). The mean age of patients was $54 \pm 9$ [26 - 85] years and $53 \%$ of those were over 60 years.

\subsection{Therapeutic Itinerary}

Before their arrival in the unit, 30 patients (59\%) had preferred a traditional healer, 17 patients (33\%) were referred by a city health officer and $4(8 \%)$ patients consulted directly by friends.

\subsection{Clinical Features}

The reasons for consultation cases of bone secondary cancers are shown in Figure 1. The pain was seen as a frequently symptom with 44 cases, or $86 \%$.

\subsection{Paraclinical Features}

$\mathrm{X}$-ray was the main radiological examination performed in patients. Bone metastases frequently sat at the spine (lumbar and thoracic), long bones and pelvis. Table 1 shows the breakdown by site of bone metastases. Figure 2 shows the distribution by site and the nature of the primary cancer that gave bone metastasis. The bone lesions were essentially condensing and lysis. Table 2 shows the radiographic features of bone lesions. The prostate 


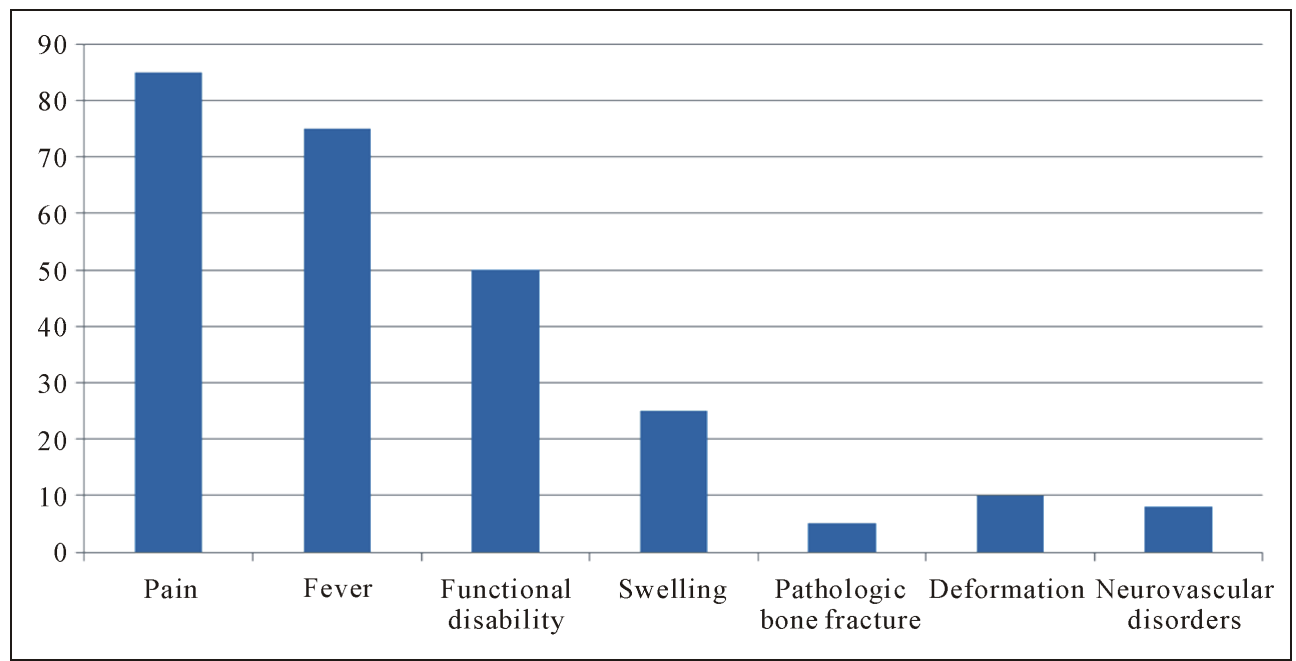

Figure 1. Distribution of the patients according to the symptoms.

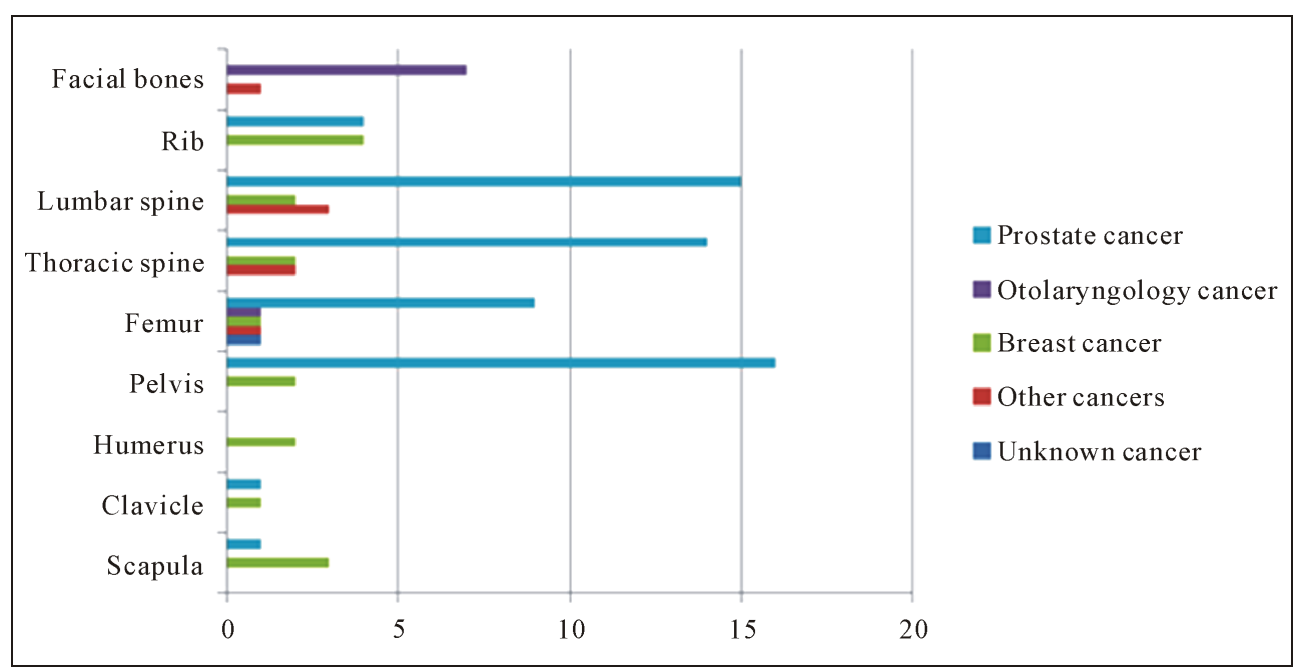

Figure 2. Distribution of the patients according to the primary cancer.

Table 1. Distribution of bone metastases.

\begin{tabular}{lcc} 
& Effective & $\%$ \\
\hline Scapula & 4 & 7.8 \\
Clavicle & 2 & 3.9 \\
Humerus & 2 & 3.9 \\
Pelvis & 18 & 35.3 \\
Femur & 14 & 27.4 \\
Spine & & \\
$\quad$ Thoracic & 18 & 35.3 \\
$\quad$ Lumbar & 20 & 39.2 \\
Rib & 8 & 15.6 \\
Facial bones & 7 & 13.7 \\
\hline
\end{tabular}


cancer gave mostly bone condensing metastases while breast cancer gave exclusively bone lysis metastases. Figure 3 shows the distribution of the type of injury according to the nature of the primary tumor that gave bone metastasis.

Metastases were inaugural in 16 cases leading to the realization of a surgical biopsy in 5 cases and percutaneous in 4 cases. Tumor markers were assayed in all patients and was contributory in 35 cases (Prostatic Specific Antigen in 23 cases, CA 15.3 in 5 cases, CA 125 in 4 cases, Alfa Foeto Protein in 2 cases and carcinoembryonic antigen in 1 case). Primary cancers are reported in Table 3.

Other secondary outbreaks were found. It was lung metastasis (18 cases), mediastinal lymphadenopathy (4 cases), and liver metastases (9 cases).

Radiation therapy is not available in our country, different therapeutic methods used were surgery (9.8\%), chemotherapy (57\%), hormone therapy (83\%) and the use of bisphosphonates (70.5\%).

Eleven (11) patients died during hospitalization and survival at 6 months was estimated at $71.4 \%$.

Table 2. Radiological features of bone metastases.

\begin{tabular}{lcc}
\hline & Effective & $\%$ \\
\hline Number of lesions & 7 & 13.7 \\
$\quad$ Unique & 44 & 86.3 \\
Multiple & & \\
Radiological lesion & 21 & 41.2 \\
Bone lysis & 22 & 43.1 \\
Bone condensing & 8 & 15.7 \\
Mixed bone lesion & 28 & 54.9 \\
Cortical periosteal reaction & 27 & 52.9 \\
a & 1 & 2.0 \\
b & 14 & 27.4 \\
\hline
\end{tabular}

a: discontinuous thin cortical blowhole; b: spiculated periosteal cortical destroyed with discontinuous reaction.

Table 3. Distribution of patients according to the primary cancer.

\begin{tabular}{cc}
\hline & Number (\%) \\
\hline Prostate cancer & $23(45.1)$ \\
Breast cancer & $14(27.6)$ \\
Cervix cancer & $5(9.8)$ \\
Otolaryngology cancer & $3(5.9)$ \\
Liver cancer & $2(3.9)$ \\
Gastro-intestinal cancer & $2(3.9)$ \\
Broncho-pulmonary cancer & $1(1.9)$ \\
Unknown primary cancer & $1(1.9)$ \\
Total & $51(100)$ \\
\hline
\end{tabular}




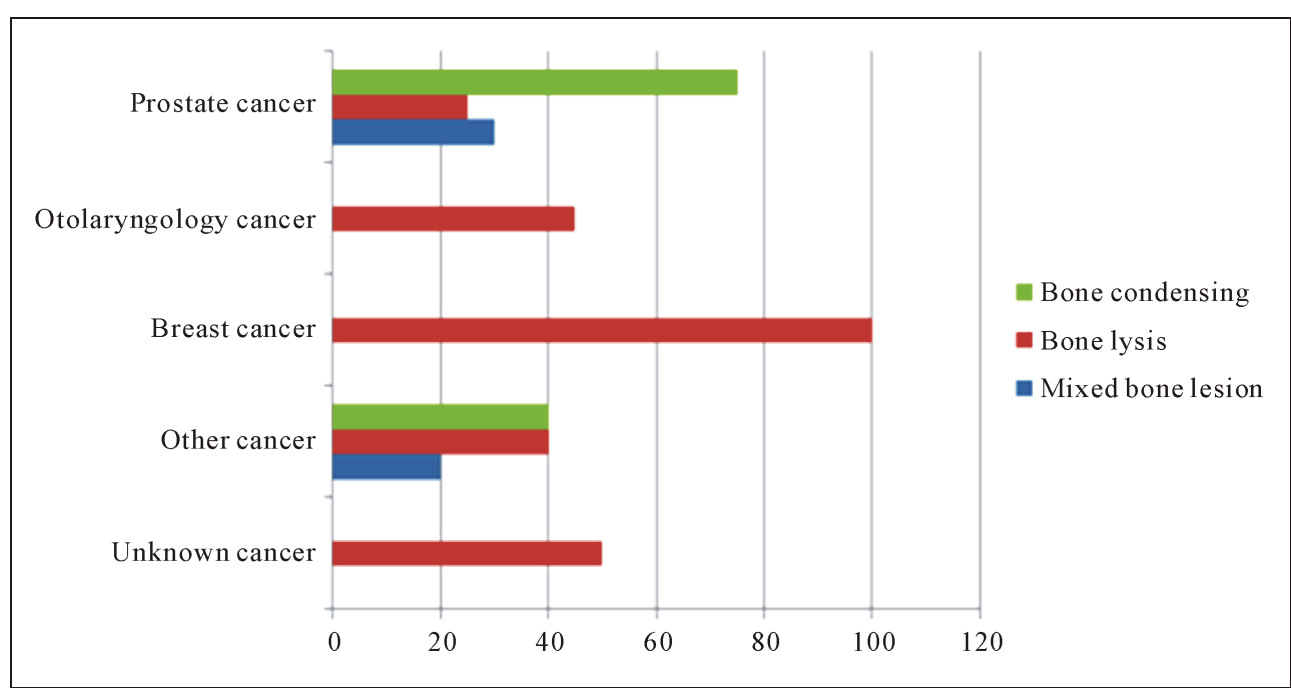

Figure 3. Type of radiological lesion of bone according to the primary cancer.

\section{Discussion}

Although Tubiana-Hulin has reported that bone metastases accounted for over $90 \%$ of malignant disease of the bone [5], they are relatively rare in our series (51 patients had bone metastases over 15 years) and other African series like the recently published works (77 cases in 19 years in Togo and 81 cases in 7 years in Congo) [6] [7]. The frequency of bone metastases is certainly underestimated in the world. Indeed, some post-mortem series seeking to determine the prevalence of bone metastases at death revealed it can reach up to 73\% [5]. Male predominance has been reported by the same authors in their series. This dominance is classic as described by many authors [8]-[12]. It seems to be explained by the frequency of prostate cancer which diagnosis is easy in our professional context [13] [14].

The mean age of patients was $54 \pm 9$ [26 - 85] years. These data were found in African work such as Kouakou in Cote d'Ivoire in 1994 [15], Ntsiba in Congo in 2013 [7] and Oniankitan in Lome in 2014 [6]. Bone metastases appear later in the Western series represented by Houze et al. and Vandecandelaere et al. who reported 77 and 63 years old for mean age of their patients respectively [14] [16].

Clinically, the main symptom was inflammatory bone pain. For Ntsiba et al. bone pain was the main mode of discovery of metastases (67.9\% of cases), followed by neurological manifestations compression (17.1\%) [7]. Oniankitan et al. [6] meanwhile, found themselves bone inflammatory pain (76.6\%), impaired general condition (75.3\%) and the compression of the spinal cord (34 cases; 44.1\%).

In X-rays, radiological lesions were usually multiple with an equal proportion of osteoblastic and osteolytic lesions. These lesions mainly sit on pelvis, spine and femur. This distribution of the lesions was found by Oniankitan [6]. The achievement of the long bones was present in $18.2 \%$ of their patients. The same observations were made in the series of Ntsiba with a majority reached at the lumbar spine (33.3\%), femur (19.0\%) and pelvis (14.3\%) [7]. These African data are similar to those published by other Maghrebian and Western authors [12] [16]. This appears as geographic distribution in the case of prostate cancer. Prostate is located in the pelvis and its cancer metastasis in pelvis, thoracolumbar spine and the femur. On the other side, the geographical distribution is less obvious in breast cancer cases. However, the extraordinary mass and exchange surface that forms the spine appears to be one explanation for the preponderance of spinal disease [16].

The distribution of the primay cancer is the same as African [6]-[12] and Western series [5] [16]. It was unknown in $1.9 \%$ of cases in our series unlike the Ntsiba where it was $6.2 \%$ [7].

\section{Conclusion}

The occurrence of bone metastases was relatively frequent in carcinomas of the prostate, breast and stomach. In our country, a good physical examination of the patient combined with radiological images allows referral to the primary tumor. 


\section{References}

[1] Lebret, T. and Méjean, A. (2008) Physiopathology, Diagnosis and Management of Bone Metastases from Prostate Cancer. Progrès en Urologie, 18, S349-S356. http://dx.doi.org/10.1016/S1166-7087(08)74566-4

[2] Destombe, C., Botton, E., Le Gal, G., Roudaut, A., Jousse, S., Devauchelle, V. and Saraux, A. (2007) Investigations for Bone Metastasis from an Unknown Primary. Joint Bone Spine, 74, 85-89. http://dx.doi.org/10.1016/j.jbspin.2006.05.009

[3] Conroy, T., Malissard, L., Dartois, D., Luporsi, E., Stines, J. and Chardot, C. (1988) Natural History and Development of Bone Metastasis. About of 429 Cases. Bulletin du Cancer, 75, 845-857.

[4] Lagrange, J.L., Pan, C., Calitchi, E., Diana, C., Muresan, M., Wu, J.F., et al. (2008) Practical Radiation Therapy for Painful Bone Metastases. Revue Du Rhumatisme, 75, 530-535. http://dx.doi.org/10.1016/j.rhum.2008.02.005

[5] Tubiana-Hulin, M. (1991) Incidence, Prevalence and Distribution of Bone Metastases. Bone, 12, S9-S10. http://dx.doi.org/10.1016/8756-3282(91)90059-R

[6] Oniankitan, O., Kakpovi, K., Kpoti, M., Houzou, P., Fianyo, E., Koffi-Tessio, V.E.S., Tagbor, K.C. and Mijiyawa, M. (2014) Profile of Secondary Bone Cancer in Lomé (Togo). Open Journal of Rheumatology and Autoimmune Diseases, 4, 192-197. http://dx.doi.org/10.4236/ojra.2014.43026

[7] Ntsiba, H., N’soundhat, N.E.L., Ndounga, E. and Ondzal, A.E. (2013) Profile of Secondary Bone Cancer in Brazzaville. Open Journal of Rheumatology and Autoimmune Diseases, 3, 251-254. http://dx.doi.org/10.4236/ojra.2013.34039

[8] Bileckot, R., Miakoundoba, R.C. and Nkoua-Mbon, J.B. (2008) Two Brazzaville Series of Bone Metastases. Carcinol Prat Afrique, 8, 57-60.

[9] Bahebeck, J., Atangana, R., Eyenga, V., et al. (2003) Bones Tumors in Cameroon: Incidence, Demography and Histopathology. International Orthopaedics, 27, 315-317. http://dx.doi.org/10.1007/s00264-003-0480-7

[10] Abdulkareem, F.B., Evesan, S.U., Akinde, O.R., et al. (2007) Pathological Studies of Bone Tumors at the National Orthopaedic Hospital, Lagos, Nigeria. Western African Journal of Medicine, 26, 306-311.

[11] Ly, M., Ly, A., Rodrigues, M., et al. (2010) Cancer in Africa, a New Health Challenge. Examples of Mali and Mali Onco Association. Bulletin du Cancer, 97, 965.

[12] Belaksir, L., Seknaji, N., Touimy, M., Janani, S., et al. (2010) Bone Metastases: Experience of Rheumatology CHU Ibn Rushd at Casa. Revue Du Rhumatisme, 77, A131-A325.

[13] Seknaji, N., Touimy, M., Belksir, L., et al. (2010) Contribution of Bone Biopsy in Search of Primary Cancer of Bone Metastases. Revue Du Rhumatisme, 77, A131-A325.

[14] Houze, P., Ranaivosoar, R., Prost, A.C., et al. (1995) Bone Metastases of Prostate Cancer: Contribution of Specific Determination of Bone Alkaline Phosphatase. Immuno-Analyse \& Biologie Specialisee, 10, 27-33.

[15] Kouakou, N. (1994) Bone Metastasis in Ivory Coast Hospital. Rhumatologie (Aix-les-Bains) A, 46, $243-245$.

[16] Vandecandelaere, M., Filipo, R.M., Cortet, B., Catanzariti, L., Duquesnoy, B. and Delcambre, B. (2004) Bone Metastases Revealing: A Comparative Study in 30-Years Intervals. Revue Du Rhumatisme, 71, 390-396. http://dx.doi.org/10.1016/S1169-8330(03)00304-1 
Scientific Research Publishing (SCIRP) is one of the largest Open Access journal publishers. It is currently publishing more than 200 open access, online, peer-reviewed journals covering a wide range of academic disciplines. SCIRP serves the worldwide academic communities and contributes to the progress and application of science with its publication.

Other selected journals from SCIRP are listed as below. Submit your manuscript to us via either submit@scirp.org or Online Submission Portal.
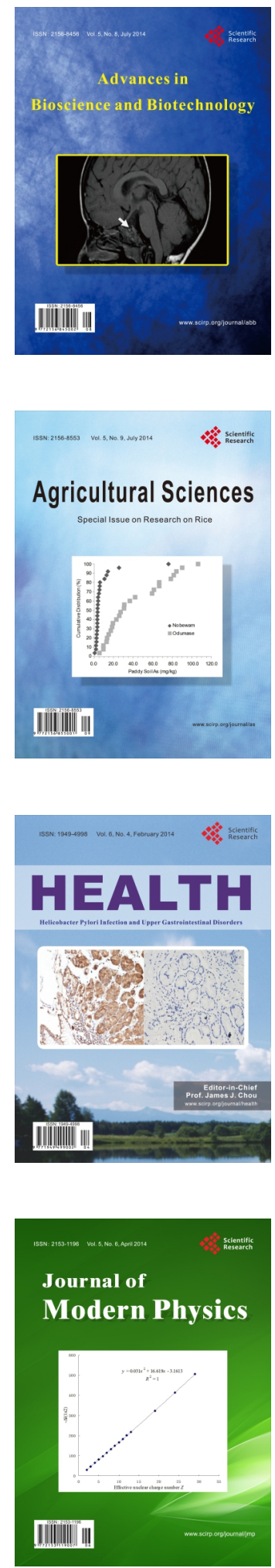
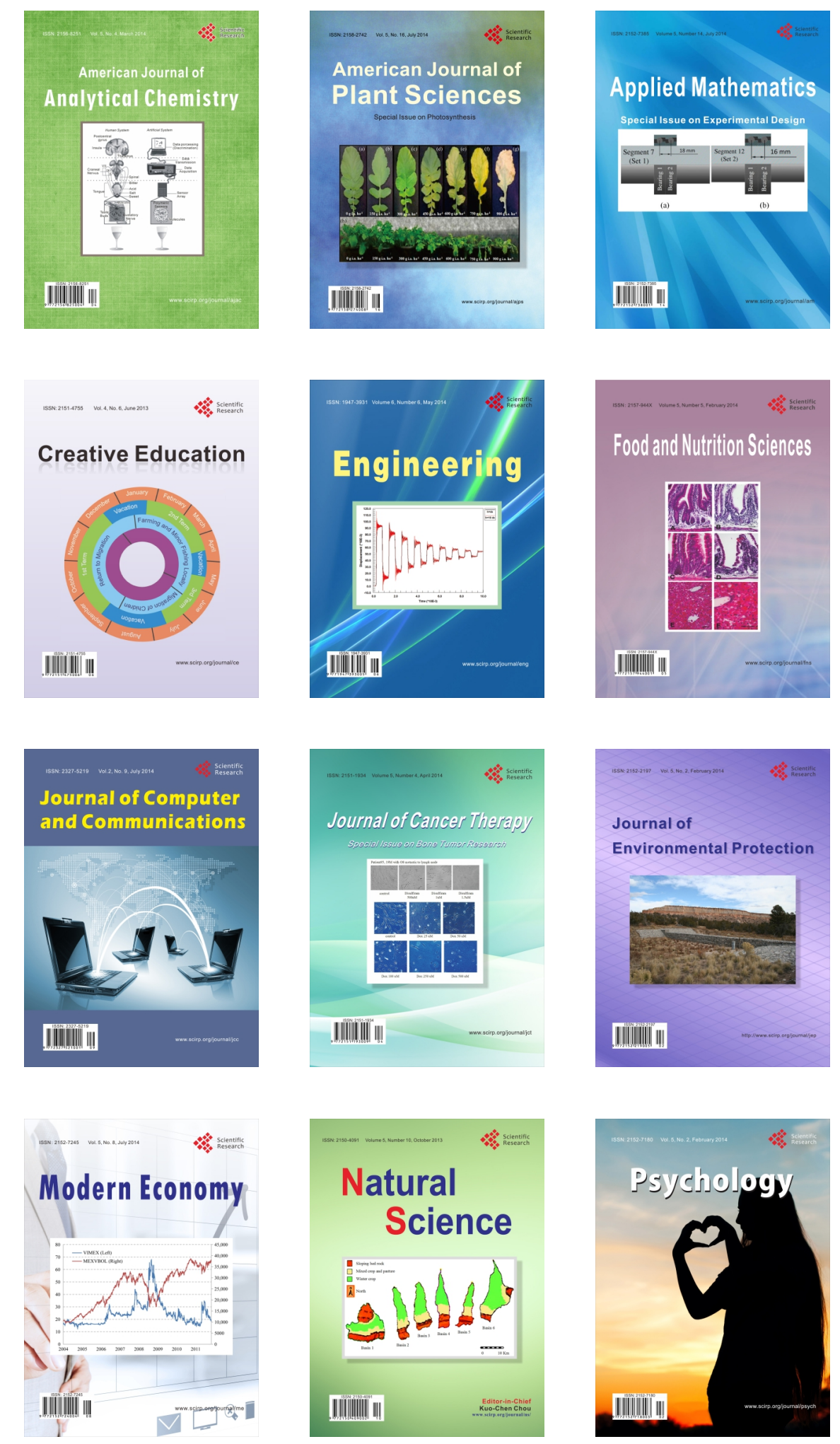